\section{Democracia obrera y radicalización en la Córdoba rebelde: El Sindicato de Trabajadores de Perkins (1972-1973)}

Diego Salerno

UNLAM - Facultad de Filosofía y Letras, Universidad de Buenos Aires, Argentina / dmsalerno@hotmail.com

Fecha de recepción: 15/9/2018. Fecha de aceptación: 7/2/2019.

\title{
Resumen
}

Este artículo forma parte de un proyecto sobre la experiencia del Sindicato de Trabajadores de Perkins (SITRAP) entre 1972 y 1976. Durante este período el SITRAP participó de una nueva fase de expansión del clasismo en Córdoba. Este trabajo analiza la implementación de una democracia obrera y el proceso de radicalización ideológica y política durante el primer año de dirección clasista del SITRAP.

\section{Worker's democracy and radicalization in the rebel Córdoba: the Trade Union of Workers of Perkins (1972-1973)}

\begin{abstract}
This article is part of a project on the experience of de Trade Union of Workers of Perkins betwen 1972 and 1976. During that period the SITRAP participated in a new phase of classism in Córdoba. This paper examines the implementation of a working democracy and the process of ideological and political radicalization during the first year of class manegement in the SITRAP.
\end{abstract}

A partir del Cordobazo de mayo de 1969 se profundiza la crisis de dominación en la Argentina. Un intenso proceso de movilización popular extendido por todo el país provocó el derrumbe definitivo del proyecto militar de la Revolución Argentina. En este contexto general, se destaca la centralidad que ocupan las luchas de la clase trabajadora. Los conflictos obreros que estallan en las principales plantas de la industria mecánica de Córdoba desde comienzos de 1970 inauguran un ciclo de "rebelión de las bases" que, del cuestionamiento inicial a la burocracia sindical enquistada en la conducción de los gremios, evolucionó hacia planteos anticapitalistas y revolucionarios en sus enfrentamientos con las empresas y con la dictadura militar. Desde entonces se desarrollaron diversos movimientos combativos y clasistas en la clase obrera de

\section{Palabras clave}

Sindicato de Trabajadores de Perkins (SITRAP) clasismo democracia obrera radicalización

\section{Keywords}

Trade Union of Workers of Perkins classism worker's democracy radicalization 
1. La Voz del Interior, en adelante LVI, 28/o9/1963, p. 13 y 03/12/1971, p. 6.

2. Ver, por ejemplo, Brennan, 1996; James, 1990; Mignon, 2014; Ortiz, 2015.
3. A partir del 2 de junio de 1970 se inició la ocupación de las plantas como parte de un plan de lucha del SMATA: KA-Renault, Grandes Motores Diésel, Perdriel, Ilasa, Thompson Ramco y Transax. Se sumaron, además, Fiat Concord, Materfer y Perkins (Mignon, 2014: 187). En Perkins, el conflicto continuó hasta mediados de julio. El resultado final fueron varias decenas de cesanteados y la consolidación de la vieja dirección sindical, no porque afirmara su representatividad entre los obreros sino porque a lo largo del proceso quedaron eliminados los líderes antiburocráticos (Schmucler, Malecki y Gordillo, 2104: 132).
Córdoba. En el presente trabajo se analiza la experiencia del Sindicato de Trabajadores de Perkins (SITRAP) como una nueva fase del clasismo cordobés. Para dar cuenta de este proceso abordaremos diversas temáticas. En primer lugar, luego de una breve reseña de los orígenes del activismo combativo en Perkins, nos centraremos en la política sindical desarrollada por la nueva dirigencia concentrándonos en las principales demandas y formas de lucha de la "democracia obrera", su participación en la CGT Regional y, en especial, su relación con el SMATA clasista. En segundo lugar, describiremos el proceso de radicalización ideológica y política que tuvo como protagonistas a la dirigencia y a las bases de Perkins. El período comprendido en nuestro análisis se ubica en la primera etapa de la experiencia clasista del SITRAP entre fines de 1972, en una coyuntura dominada por el auge de la combatividad del movimiento obrero de Córdoba, y principios de 1974 cuando los sucesos del Navarrazo implicaron una transformación importante del escenario político-sindical en la provincia.

La fábrica de Motores Perkins Argentina, ubicada en Ferreyra, en la periferia industrial del sudeste de la ciudad de Córdoba, comenzó sus actividades en 1961. Originada en una inversión de capitales nacionales de 400 millones de pesos, surge por un acuerdo con la empresa Perkins de Peterbrough, Inglaterra, para producir una amplia gama de motores diésel. Por ese entonces, la mano de obra estaba compuesta por alrededor de 250 obreros, 20 supervisores y 80 administrativos. Contaba, además, con oficinas comerciales en la ciudad de Buenos Aires. La empresa fue ampliando paulatinamente sus instalaciones e incorporó la producción de nuevos modelos para autos, tractores y compresores de aire. Al cumplirse el décimo año de su creación la producción llegaba a 75.000 motores. Además, se alcanzaba una de sus principales metas: la integración de partes nacionales casi en su totalidad (82\%). Esta expansión permitió un aumento de su plantel de trabajadores hasta alcanzar una cifra superior a los 700 operarios, predominantemente trabajadores no calificados dedicados a la producción masiva. La representación gremial, a su vez, se organizó a partir de un sindicato de empresa: el Sindicato de Motores Diésel Livianos (SMDL). ${ }^{1}$

En las interpretaciones sobre el "clasismo" ${ }^{2}$ aparecen una serie de elementos constitutivos comunes como la movilización de base por motivos laborales, el desarrollo de formas autónomas de organización en la fábrica y un posterior proceso de radicalización ideológica hacia posturas socialistas. Partimos de la caracterización del sindicalismo clasista como una línea para la acción en el seno de las organizaciones sindicales basada en la combinación de la lucha reivindicativa con la lucha por una transformación de raíz de la sociedad capitalista (Laufer, 2017: 132-133). Son sus rasgos principales el ejercicio de la democracia sindical, el choque con las dirigencias burocráticas y conciliadoras, el desarrollo de formas de lucha radicalizadas, la reivindicación de la lucha por el ejercicio del control obrero de la producción y los esfuerzos de unidad y coordinación con otros sectores obreros y populares.

\section{La rebelión de las bases y los orígenes del Movimiento de Recuperación Sindical de Perkins (MRSP)}

La conducción del SMDL era ejercida desde la creación de la entidad gremial por Francisco Angulo como Secretario General. Relacionado en sus inicios como dirigente con la Democracia Cristiana, se integró luego al sector ortodoxo de la dirigencia sindical peronista y formó parte de las 62 Organizaciones y de la CGT de los Argentinos en tiempos del Cordobazo. Su estilo sindical favorecía una relación armónica con la empresa para lo cual se mantenía una débil organización con escasa afiliación y un férreo control del activismo opositor.

Sin embargo, los trabajadores de Perkins se sumaron a la rebelión de las bases participando de las huelgas salvajes con ocupación de fábrica de junio de $1970 .{ }^{3}$ Allí se 
manifestó una dura la oposición a la dirección gremial. Poco tiempo después, durante el año 1971, surgieron pequeños núcleos de activismo combativo por la influencia pertinaz de los clasistas de SITRAC-SITRAM. ${ }^{4}$ La empresa, por su parte, sostenía una postura inflexible que condicionaba las posibilidades de desarrollar una actividad sindical antiburocrática: "Los compañeros de base manifestaban el repudio (...) en silencio, con indiferencia, y en ciertos momentos espontáneamente (...) El temor que existía en los compañeros de base era lógico, y no era para menos, puesto que los que consecuentemente demostraban su disidencia eran despedidos". 5

Una nueva camada de militantes de izquierda reanudó a comienzos de 1972 la oposición a la dirección del sindicato. En su mayoría, jóvenes y migrantes del interior cordobés, muchos con estudios secundarios en escuelas técnicas y, en especial, con escasa o nula participación política y sindical.

En sus relatos describen su ingreso a las fábricas y el inicio de su politización. Por ejemplo, Américo Aspitia, uno de ellos, nació en Villa del Soto, un pueblo del noroeste cordobés. Allí su familia se dedicaba al trabajo agrícola: "Mis padres han sido gente de campo, gente de chacras, cultivo de algodón, siempre, yo me crié en el medio de los algodones y el garbanzo, siempre trabajando la tierra". Años más tarde, ya adolescente, pudo estudiar en una escuela- fábrica y al recibirse de técnico mecánico en 1959 tomó la decisión de emigrar a la ciudad de Córdoba que vivía en ese momento un auge de sus industrias mecánicas. Ingresó en la empresa Kaiser Argentina en la dura sección de forja, pero al poco tiempo quedó cesante. En esa época, alrededor del año 1963, no tenía participación en la actividad sindical: “(...) y seguramente era por mi formación (...) los sindicatos aparecieron como una cuestión así medio sospechosa, no era bueno digamos, no era bueno pertenecer porque (...) estaban dominados por los comunistas, por los que querían hacer lío, esa era la visión que yo traía de allá".

Luego de deambular por varias pequeñas empresas metalúrgicas, logró ingresar a Fiat Materfer, "trabajando 10 horas a veces, soldando permanentemente", pero permaneció allí pocos meses, ya que durante el año 1967 consiguió un mejor puesto de trabajo, más calificado, en la sección línea de montaje de la empresa Perkins". 6

Por su parte, Juan Enrique Villa, secretario general del SITRAP a partir de 1975, nació en Cruz del Eje, ciudad del noroeste de Córdoba. Como muchos de sus futuros compañeros de la conducción del sindicato finalizó sus estudios secundarios. En 1965 se recibió de maestro y decidió emigrar a la ciudad de Córdoba para ingresar en la Universidad en la carrera de Derecho. Iniciaba, al mismo tiempo, su militancia en el MALENA (Movimiento de Liberación Nacional). Sin embargo, luego de realizar el servicio militar en 1967 comenzó su experiencia como obrero de fábrica.7

Al relatar su ingreso a Perkins describe la estrategia patronal para reclutar "obreros nuevos" en el interior de la provincia:

El jefe de personal de la empresa era un tal Guzmán, de Villa del Soto, y tenía una especie de agencia de empleo en Cruz del Eje. En la Tecnológica nos recibíamos de maestros y a ellos les convenía porque obtenían mano de obra calificada. Además, éramos medio paisanos, buenitos y no estábamos muy avivados de nada. Pobre Guzmán, al final, de los contratados de Cruz del Eje, unos cien más o menos, todos le salieron activistas (Tejerina et al, 2010: 105-106).

Y Juan Villa fue uno de ellos:

Me decían la Víbora porque aparecía zigzagueando, dejaba las piezas y rajaba. Como era el encargado de proveer la línea de montaje, iba y venía. Por una punta entraba el
4. Sindicato de Trabajadores de Fiat Concord y Sindicato de Trabajadores de Fiat Materfer. Entre julio de 1970 y hasta la disolución de ambas entidades en octubre de 1971 fueron la referencia principal del sindicalismo clasista. Junto al trabajo de los activistas de Fiat en busca de tejer vínculos con el conjunto de los trabajadores de Ferreyra influyó la cercanía de las fábricas y la relación de parentesco entre obreros para el surgimiento de pequeños grupos opositores en Perkins. 5. Boletín del SITRAP Extra, en adelante, BSE, 04/1974, p.4.

6. Américo Aspitia. Secretario Gremial del SITRAP. Se incorporó a la militancia política en el Peronismo de Base. Entrevista realizada el 19 de marzo de 2014 en la ciudad de Villa Allende (Córdoba). Entrevistador: Diego Salerno.

7. Juan Villa. Secretario General del SITRAP desde 1975. Fue parte de "El Obrero". Esta organización política de Córdoba fue creada en 1971 por militantes del Malena. Hacia 1974 confluyó junto a otras agrupaciones en la formación de la Organización Comunista Poder Obrero (OCPO) que propicio la lucha armada como estrategia política. Entrevista realizada el 20 de marzo de 2014 en la ciudad de Córdoba. Entrevistador: Diego Salerno. 
8. BSE, 04/1974, p. 4. Fue importante la influencia en Perkins del Movimiento de Recuperación Sindical del SMATA. Esta agrupación sindical organizó la lista Marrón que en abril de 1972 triunfó en las elecciones de renovación de autoridades resultando electo René Salamanca como secretario general del SMATA. Se iniciaba de esta manera una nueva experiencia clasista en Córdoba.
9. Archivo del SITRAC, Subarchivo N. - 19, Ficha 29, Revista Desacuerdo NN. ${ }_{17}, 03 / 01 / 1973$, p. 3. Los delegados paritarios fueron Miguel Agüera, Juan Villa y Anacleto Fuentes. SMATA, sigla del Sindicato de Mecánicos y Afines del Transporte Automotor. 10. BSE, 04/1974, p. 2.

11. Esta lista tuvo su origen en el Grupo de Recuperación de Decencia Sindical que se formó en 1971. Esteban Carranza. Secretario Adjunto del SITRAP a partir de 1975. Entrevista realizada el 20 de julio de 2014 en la ciudad de Córdoba. Entrevistador: Diego Salerno. block pelado y por la otra salía el motor listo para inspección. En medio había 30 o 40 puestos distintos. Yo los proveía y eso me permitía hablar con todos. Y hacer política (Tejerina et al, 2010: 105-106).

Durante el mes de abril de 1972 surge un nuevo esbozo de organización, los 'Obreros Combativos de Perkins' que participó en las elecciones de delegados en el mes de mayo resultando elegidos cinco de sus candidatos. Posteriormente se organizó el Movimiento de Recuperación Sindical de Perkins. ${ }^{8}$ El apoyo cada vez más amplio entre las bases les permitió avanzar sobre los decisivos cuerpos orgánicos del sindicato: sus activistas fueron elegidos para la Comisión Interna de Reclamos, y también, como representantes para negociar con la empresa un nuevo Convenio Colectivo de Trabajo.

En la siguiente entrevista de enero de 1973, los delegados paritarios describen sus estrategias entre las bases y los vínculos con los sectores más radicalizados del movimiento obrero de Córdoba durante el proceso de negociación de los convenios colectivos. Resaltamos en este discurso, tanto las propuestas organizativas para encarar la negociación, como el tono politizado con críticas a la conducción nacional de la CGT y al gobierno militar. Esta politización temprana fue una de las manifestaciones concretas de la experiencia de los activistas clasistas de Perkins.

(...) - ¿por qué creen Uds. que las paritarias fueron llamadas en este momento?

-Los paritarios de Perkins creemos que la dictadura, con su ministro San Sebastián, de acuerdo con Rucci, Coria y con las 62 Ortodoxas, trata de ganar tiempo y darse un cierto respiro hasta fin de año. Largaron la fecha del 20 de octubre como plazo para la entrega de los anteproyectos de convenio, para no dar tiempo a que se discutan en las bases, para que haya poca información y poca movilización. Pero en Perkins y en el SMATA de Córdoba les falló la cosa y los paritarios fueron elegidos en asamblea. En Perkins, todos los paritarios fuimos elegidos en una asamblea que los burócratas de la Comisión Directiva no pudieron controlar, incluso se les impuso que votaran todos los compañeros, tanto afiliados como no afiliados, y se impidió que fuera a la paritaria el burócrata Angulo que es secretario general del sindicato.

- ¿Es posible coordinar la acción de los paritarios de los gremios de Córdoba?

-Tenemos mandato de asamblea para tomar contacto con todas las paritarias de Córdoba, ya se ha tomado contacto con la del SMATA y otras más y se está por formar una coordinadora para unificar la lucha por todos los puntos que tengamos en común en los anteproyectos, como ser la lucha por los salarios y la rediscusión de las paritarias cada tres meses. Esta coordinadora deberá, incluso, exigir a la CGT local que asuma la lucha. ${ }^{9}$

Para febrero de 1973 fueron convocadas las elecciones para designar una nueva Comisión Directiva del SMDL. El Movimiento de Recuperación Sindical de Perkins convocó a una asamblea donde se eligieron los candidatos de la lista Marrón, "compañeros representativos y jugados en la lucha". ${ }^{10}$ Las otras listas que se presentaron fueron la Azul y Blanca de la burocracia oficialista y la Azul de la agrupación "26 de julio" del peronismo combativo. ${ }^{11}$ Durante la campaña electoral, el oficialismo intentó evitar una posible derrota con maniobras en los padrones que dejaban a muchos trabajadores sin poder votar y recurriendo a las habituales denuncias ideológicas -las paredes de los baños fueron escritas con propaganda anticomunista acusando de "bolches" a los candidatos de la lista Marrón-. A su vez, los clasistas trataron de influir en el desarrollo de los comicios con sus propias tácticas. Uno de sus referentes, recuerda que: 


\begin{abstract}
...le dijimos a cada compañero que sabíamos que nos iba a votar a nosotros: entren al cuarto oscuro, por supuesto pongan el voto de la lista nuestra y saquen dos votos de la lista de ellos, nada más que dos. Entonces los fiscales de ellos cada tanto entraban a verificar y veían que los votos de ellos iban bajando. ${ }^{12}$
\end{abstract}

Luego de la sorpresa por el triunfo de la Marrón, el secretario general Angulo se dirigió a la Gerencia de Personal para informar los resultados del escrutinio. Al ingresar al despacho le dijo a Guzmán, jefe de personal: "Vengo a comunicarle que ganaron los zurdos". ${ }^{13}$ En efecto, el 2 de febrero de 1973 la lista Marrón logró una resonante victoria. Obtuvo 270 votos contra los 136 logrados por la lista Azul y Blanca y los 75 votos de la lista Azul.

\section{La conducción clasista del SITRAP y la política sindical}

El 9 de febrero de 1973 asumieron las nuevas autoridades. Los principales cargos de la Comisión Directiva los ocuparon Miguel Ángel Agüera (Secretario General), Carlos Ceballos (Adjunto), Américo Aspitia (Gremial), Mercedes Fuentes (Administrativo), Víctor Morales (Secretario de Actas), Juan Carlos Polanco (Secretario Asistencial) e Higinio Ríos (Tesorero). Para la nueva conducción la recuperación del sindicato se consideraba sólo un primer paso: "Los trabajadores de Perkins hemos logrado democratizar nuestro sindicato, pero esta victoria no es un fin en sí misma, sino la herramienta mediante la cual podemos expresar nuestra voluntad de afianzar las conquistas obtenidas y dar la lucha para la solución de los múltiples problemas que nos afligen". ${ }^{14}$

Por ese entonces, a comienzos del mes de marzo, se firmó el nuevo convenio colectivo de trabajo -el anterior databa de 1969-. Las mejoras introducidas fueron, en especial, de orden salarial. Se fijó un aumento en los salarios básicos del $32 \%$ a partir del $1^{\circ}$ de enero y de un 15 más a partir del $1^{\circ}$ de julio y se incrementaba un 50\% el premio por asistencia. También se incluyeron cláusulas que obligaban a la empresa a realizar mejoras en el comedor del personal y otorgar un local sindical dentro de la planta. Es importante resaltar, en especial, las atribuciones de la Comisión Interna de Reclamos que cobraban una nueva significación al producirse el cambio de conducción gremial ya que fortalecían el funcionamiento de una democracia de bases. Se establecía que su función principal era presentar los reclamos relacionados con las tareas del personal, la sección y los delegados en las reuniones semanales con la empresa. ${ }^{15}$

En la agenda de reivindicaciones gremiales las demandas relacionadas con las condiciones de trabajo ocuparon un lugar central. Entre las prioridades figuraba la denuncia de insalubridad de algunos sectores de la planta como la Sala de Pruebas de Motores: En un galpón de aproximadamente 80 metros de largo y 13 de ancho trabajaban 95 operarios y funcionaban 36 bancos donde se probaban los motores en marcha a altas revoluciones. Allí, "el ruido ensordecedor, los gases emanados (monóxido de carbono), y las vibraciones en el piso", eran causantes de enfermedades como "sordera, úlceras, gastritis, nerviosismo, amnesia parcial", entre otras afecciones. Además, se consideraba que "el problema se agudiza con la presión de la empresa por aumentar la producción, sin mejoras técnicas ni aumento de personal, en condiciones anormales (ambiente ruidoso y contaminado), dando como resultado mayor deterioro físico y agotamiento a las pocas horas de trabajo". Por todo esto, se exigió una jornada de seis horas. ${ }^{16}$

Otro aspecto relevante era la atención médica de los trabajadores. Se denunciaba la aplicación de la "medicina de la aspirina"-inmediata receta para resolver "cositas de nada"- que utilizaban los médicos de la empresa. Por ello, se le exigió a la patronal
12. Higinio Ríos. Miembro de la Comisión Directiva del SITRAP. Entrevista realizada en la ciudad de Córdoba el 21 de julio de 2014. Entrevistador: Diego Salerno.

13. Ibídem.

14. Archivo del SITRAC, Subarchivo 17, Ficha 2, Boletín del SITRAP, N.․ㅜ 2 , mayo/1973, p. 3, en adelante BS. Se conservan solamente los números 1 (abril), 2 (mayo), 4 (agosto) y 5 (octubre) todos del año 1973 y el Boletín Extra de abril de 1974.

15. Convenio Colectivo de Trabajo entre el Sindicato de Motores Diesel Livianos y Perkins Argentina S.A.I.C. firmado el 31 de enero de 1973.

16. BSE, o4/1974, p. 42. 
18. BS, N. 5, 10/1973, p. 1.

19. BSE, o4/1974, p. 36.

2o. LVI, $04 / 12 / 1973$, p. 13.

21. Confrontando "con algunas posiciones de apaciguamiento, de intentos de frenar la movilización, de diferenciar en el carácter de ecordación, si era o no una fiesta y donde hasta la palabra paro era cuestionada" BE, 04/1974, p. 28.

22. BS N.․ 2, 23/05/1973, p. 3. que "los médicos de planta, los deben proponer los obreros, así tendremos un profesional preocupado por la salud de los trabajadores, y no preocupado por aumentar la producción aun a costa de nuestra salud". ${ }^{17} \mathrm{El}$ sindicato, además, incorporó asesores médicos, aportados por el activismo de izquierda, para analizar las condiciones de salubridad en la planta y definir las demandas a presentar a la empresa.

Una cuestión fundamental para la Comisión Directiva fue la relacionada con las categorías. En el mes de marzo se inició una extensa y dura negociación por la revaluación de tareas. El reclamo gremial se basaba en la desactualización de la reglamentación: “(...) han pasado más de cinco años y seguimos con la misma revaluación de tareas, mientras que en todos los lugares se han agregado más trabajo, mejoras técnicas y nuevas tareas que hace a un mayor esfuerzo físico y mental de todos los compañeros". ${ }^{18}$ El sindicato realizó un estudio a partir de los aportes de trabajadores de cada una de las secciones y elaboró un anteproyecto que cubría todas las tareas de la planta. Recién en octubre empezó a funcionar la paritaria. La empresa rechazó la propuesta sindical argumentando que "la paritaria era para interpretación y no para modificar el convenio colectivo vigente en ese momento". ${ }^{19}$ Esta decisión motivó un plan de lucha -trabajo a desgano- que se extendió durante varios meses del año 1973. Finalmente, en noviembre el Ministerio de Trabajo decretó la conciliación obligatoria (ley 14.786). Se esgrimía que, en el contexto del Pacto Social, las medidas de fuerza generaban una sensible merma de la producción, "no siendo por lo tanto el medio idóneo en esta emergencia, teniendo en cuenta los propósitos de reconstrucción y liberación en que está empeñado el gobierno de la Nación, y la importancia de la actividad en la economía de la Nación". ${ }^{20}$

Las iniciativas de democracia sindical de la conducción del SITRAP aseguraron la movilización permanente de las bases. Las asambleas obreras fueron el ámbito principal para la toma de decisiones. Por ejemplo, a fines de mayo la convocatoria se realizó para decidir las posturas del sindicato para el plenario de la CGT previo al IV aniversario del Cordobazo. En la misma se votaron dos mociones importantes. Una apoyando la prórroga del mandato del Secretariado de la CGT regional por 60 días que marcaba el apoyo del SITRAP a la conducción ejercida por Agustín Tosco y Atilio López. Otra, relacionada con las actividades de conmemoración del Cordobazo, proponiendo "abandono de tareas a las 10 horas con asambleas en los lugares de trabajo para marchar luego a un acto central en la CGT o plaza Vélez Sarsfield de toda la clase trabajadora de Córdoba". En el plenario la resolución final tuvo en cuenta parte de la propuesta del SITRAP ${ }^{21}$ que fue acompañada, además, por el SMATA. El balance de la participación fue, para los "nuevos" de Perkins, auspicioso: "Debemos decir que para nosotros fue muy importante este plenario, pues nos dejó mucha experiencia, y más que todo vimos que nuestra posición fue tomando gran envergadura (...) el peso de nuestra propuesta, conjuntamente con SMATA, se debió en gran medida a que fueron los únicos sindicatos que llevaron moción de asamblea (...)". ${ }^{22}$

Los éxitos de los clasistas de Córdoba eran cada vez más evidentes (Brennan, 1996: 327). El clasismo se expandió favorecido por el clima político de la ciudad y "por los esfuerzos de militantes capaces que habían trabajado durante años en las plantas y que ahora veían una oportunidad de realizar lo que antaño debían haber parecido las imposibles ensoñaciones de los revolucionarios" (Brennan, 1996: 327). Los movimientos antiburocráticos que intentaban la "recuperación de sindicatos" cobraron un inusitado impulso: junto a los bastiones del sindicalismo disidente, a los que se sumó el SITRAP, surgieron diversas iniciativas entre las bases del caucho, calzado, sanidad, construcción, empleados públicos y docentes, entre otros. Estos activistas enfrentados a las anquilosadas direcciones peronistas, ampliaron su influencia y ocuparon paulatinamente espacios en los Cuerpos de Delegados, Comisiones Internas de Reclamos y Comisiones Provisorias. Desde estas intentaron completar el proceso de recuperación de los sindicatos. Fueron durante este período, protagonistas permanentes de la "rebelión de las bases". 
Durante junio recrudeció el conflicto entre el SMATA y la Unión Obrera Metalúrgica (UOM) por la afiliación de los trabajadores de FIAT, irresuelta desde la disolución de SITRAC y SITRAM en octubre de 1971. El gobierno nacional había otorgado a la UOM la afiliación de los obreros de Fiat. A su vez, René Salamanca, secretario general del gremio mecánico y uno de los referentes del clasismo cordobés, "contando con el verdadero animo de las bases", intentó fortalecer su posición por medio de un plebiscito. La consulta a las bases se realizó durante los días 24 y 26 de junio de 1973. El triunfo de la posición del SMATA fue aplastante. En Concord su propuesta obtuvo 1502 votos contra 153 y en Materfer 652 contra 58. Fortalecido por estos resultados, el 11 de julio Salamanca anunció en conferencia de prensa la intención de afiliar formalmente al SMATA a los trabajadores de las plantas de Fiat y sumar también a los de Perkins. Además, se decidió constituir un Cuerpo de Delegados único para todas las fábricas mecánicas. Este hecho marcaba la intención de consolidar un poderoso bloque sindical de más de 18.000 trabajadores con influencia decisiva para el conjunto del movimiento obrero de Córdoba. ${ }^{24}$

Por su parte, la conducción del SITRAP decidió apoyar los proyectos de Salamanca: "La razón fundamental es la solidaridad de clase. Los obreros debemos tender a agruparnos en grandes sindicatos por rama de la producción para resistir con mayor fuerza los embates de nuestros enemigos de clase, patrones y Estado, con sus organismos de seguridad: policía, gendarmería, ejército". ${ }^{25}$

Sin embargo, también se evaluaban las ventajas de los sindicatos por empresa porque "son más fáciles de recuperar de manos de la burocracia". La decisión quedó en manos de las bases que mediante un plebiscito -llevado a cabo el 2 de julio-votaron a favor de la afiliación al SMATA. ${ }^{26}$

El sindicato cumpliendo el mandato de la asamblea comenzó a entregar las fichas de afiliación para presentar al Ministerio de Trabajo e informó que:

...lo más importante y que hay que recalcarlo, es que ya de hecho nos encontramos funcionando mancomunadamente en todos los aspectos con los compañeros del SMATA, y esa unidad se demuestra en las distintas reuniones del cuerpo único de delegados y en las distintas asambleas que se han venido realizando y en las cuales han participado compañeros de base de Perkins. ${ }^{27}$

El conflicto entre el SMATA y la UOM se agravó durante el mes de agosto cuando se produjo la toma de la planta de Concord. Durante estas jornadas los trabajadores del SITRAP tuvieron una destacada participación. En la siguiente crónica se describen esos acontecimientos:

El 20 de agosto de 1973, se lleva a cabo por parte de los obreros, la toma con rehenes de las instalaciones fabriles de Fiat Concord, el objetivo era conseguir el libre encuadramiento sindical. Esta actitud activa y combativa encuentra eco en forma casi inmediata en los trabajadores mecánicos, principalmente de Ferreyra, (...) expresada en abandono de tareas con manifestaciones, convergiendo a las puertas de la planta tomada. La actitud nuestra es digna de destacar, ya que junto a Thompson Ramco y Grandes Motores Diésel, fuimos los más consecuentes en brindar nuestro total e incondicional apoyo a los compañeros de Concord. El grado de conciencia solidaria de los compañeros de Perkins, llega a su punto culminante cuando en el tercer día, el turno de tarde en asamblea decide marchar hacia Santa Isabel, y allí, en una asamblea realizada con los dos turnos de IKA-Renault se logra imponer nuestra dinámica expresada en los días anteriores a estos compañeros, que después de la asamblea conjuntamente con nosotros, se dirigen en caravana hacia las puertas de Fiat. Pero no
23. LVI, 27/06/1973, p. 16.

24. LVI, 12/07/1973, p. 16; LVI, 26/o7/1973, p. 11.

25. BSE, 0471974, p. 32.

26. Ibídem.

27. Ibídem. 
28. BSE, 04/1974, pp. 22, 23 y 24.

29. Ibídem.

30. James Brennan. El Cordobazo. Las guerras obreras en Córdoba, (1955-1976). Buenos Aires: Sudamericana, 1996, p. 319.

31. LVI, 28/o6/1973, p. 9.

32. LVI, 29/06/1973, p. 11.

33. Formalmente peronistas pero en la práctica más independientes y pluralistas con respecto a la representación sindical. Su referente era Atilio López de la Unión Tranviarios Automotor (UTA), vicegobernador de Córdoba y Secretario General de la CGT Regional desde 1971. Sumaban el apoyo de cerca de 25 gremios (Servetto, 1998: 77). 34. Se definían como auténticos peronistas y exigían una CGT local alineada con la CGT Nacional. Sus referentes eran Alejo Simó de la Unión Obrera Metalúrgica (UOM) y Mauricio Labat, del sindicato de taxistas. Controlaban alrededor de 25 gremios (Ferrero, 1995: 25). 35. LVI, 28/07/1973, p. 11.

36. Diario Córdoba, 01/08/1973, p. 5. La lista incluye a Luz y Fuerza, Gráficos, Viajantes, Prensa, Publicidad, Construcción, Petroleros, FADUC (Docentes Universidad Nacional de Córdoba) y ATEPSA (seguridad), del sector de gremios Independientes y SMATA, SITRAP y el Sindicato de Trabajadores del Caucho y Afines (SITRACAF) que se identificaban como No Alineados o Clasistas. 37. LVI, 02/o8/1973, p. 6. pudimos lograr nuestro fin, ya que la represión policial, como en las mejores épocas de la dictadura, no pudo estar ajena a esta circunstancia, y es así que, al llegar a la rotonda del Matadero, fuimos atacados y disueltos con gases y a garrotazos. ${ }^{28}$

Al realizar el balance de los sucesos se sostenía que:

Nosotros consideramos que la causa fundamental que impidió el conseguir los objetivos propuestos desde el principio, fue la falta de profundización y extensión de la lucha, que se debió dar en un nivel más generalizado e intenso en la totalidad de los compañeros mecánicos con la dirección de la CGT regional, cuya intervención en este conflicto dejó mucho que desear. ${ }^{29}$

Hacia finales del año 1973 el conflicto seguía sin resolverse y era evidente la actitud dilatoria del ministro de Trabajo Ricardo Otero que beneficiaba a la UOM.

La consolidación en Córdoba de este sindicalismo disidente va a provocar la reacción del gobierno y de la cúpula nacional de la CGT. Perón sabía bien que el éxito de la campaña verticalista dependía de Córdoba. El restablecimiento de la autoridad cegetista era necesario tanto para controlar la expansión de la militancia obrera en todo el país como para asegurar el éxito del Pacto Social. ${ }^{30}$ En este contexto se desplegó una ofensiva en varios frentes: Por un lado, se determinó que quedaban "sin efecto las actuales conducciones gremiales a cargo de las Delegaciones Regionales de la CGT de todo el país, incluso las Comisiones Provisorias que se encuentran en funcionamiento, todo a partir del $1^{\circ}$ de julio de $1973 " .{ }^{31}$ Por otro, se decidió la unificación del sindicalismo peronista (ortodoxos y legalistas) en las 62 Organizaciones de Córdoba para suprimir, de esta manera, la alianza entre legalistas, independientes y clasistas que conducía la CGT local y poder avanzar hacia una dirección exclusivamente peronista. Además, se recurrió con mayor ímpetu a la denuncia de infiltración marxista y recrudecieron las acciones de violencia contra los disidentes. Las acusaciones recaían, en especial, sobre Agustín Tosco por ser "uno de los principales responsables de los asaltos a las organizaciones gremiales" y sobre el Poder Ejecutivo provincial por "la complaciente actitud del vicegobernador Atilio López. Se está permitiendo que el marxismo cope los sindicatos desde la misma Casa de Gobierno". ${ }^{32}$

El 27 de julio se reunió en la localidad serrana de Valle Hermoso el plenario de las "62 Organizaciones" cordobesas. Contando con la presencia del ministro de Trabajo Ricardo Otero, de Lorenzo Miguel y del cuestionado gobernador Obregón Cano, se eligieron las nuevas autoridades. La nueva mesa directiva se conformó con cuatro representantes "legalistas" 33 y cuatro "ortodoxos". ${ }^{34}$ Además, Lorenzo Miguel leyó el acta en la cual se hacía constar la disolución de los sectores internos del peronismo gremial y el acatamiento a las "Veinte Verdades del Justicialismo" y a la verticalidad del movimiento. 35

Desde ese entonces, se produjo un nuevo reagrupamiento del sindicalismo disidente de Córdoba: el $1^{\circ}$ de agosto de 1973 se dio a conocer la formación del Movimiento Sindical Combativo (MSC), integrado por doce gremios ${ }^{36}$ y treinta agrupaciones de base. ${ }^{37}$ Surgía, de esta manera, una nueva coalición entre los gremios de izquierda (independientes y clasistas) bajo la conducción de Agustín Tosco de Luz y Fuerza y René Salamanca de SMATA. Esta iniciativa contó con el apoyo y la plena participación de los dirigentes de Perkins, en especial de Juan Villa.

Hacia fines de 1973 el gobierno nacional implementó una nueva política disciplinadora con la sanción de la ley de Asociaciones Profesionales. En Córdoba se realizaron numerosos debates y asambleas donde participaron trabajadores, estudiantes y profesionales para cuestionar el proyecto gubernamental. 
Según el punto de vista del SITRAP la nueva ley, sancionada el 29 de noviembre de 1973: ...fue elaborada por la más alta expresión de la burocracia sindical (CGT Nacional y Ministerio de Trabajo), sin ningún tipo de consulta (...) nace como una necesidad (...) de acentuar su control y amordazar al movimiento obrero, dada el alza y la tendencia manifestada estos últimos tiempos a recuperar sindicatos, ya sea mediante tomas de los lugares de trabajo, asambleas, etc., hechos éstos que hacían peligrar la permanencia de los burócratas sindicales. ${ }^{38}$

Además se rechazaban diversas disposiciones de la ley como: la extensión de los mandatos de las comisiones directivas a cuatro años; el control de las Federaciones del régimen electoral; la prohibición de la actividad política partidaria, reservando a las cúpulas tal derecho; la facultad de las Federaciones para intervenir a las asociaciones de primer grado; la posibilidad de intervención directa del Estado en los sindicatos a través del Ministerio de Trabajo y la reforma de los estatutos sin asegurar la participación de las bases. Con respecto a los sindicatos por empresa -como era el SITRAP- el artículo 22 de la ley planteaba su legalidad "cuando no exista en esa actividad otro con personería gremial" o el encuadramiento dentro de una asociación por rama de actividad. ${ }^{39}$

Durante esta primera etapa de experiencia clasista que transcurre durante 1973 el Sindicato de Trabajadores de Perkins impulsó un modelo de democracia obrera contando con la fortaleza de su núcleo activista y con la participación de sus bases. Por otra parte, se insertó en el movimiento obrero cordobés en apoyo de la conducción de la CGT Regional. A la vez desarrolló una vinculación estrecha con el SMATA y propició con su solidaridad la expansión de movimientos antiburocráticos en varios sindicatos.

\section{El proceso de radicalización política e ideológica}

En el siguiente apartado nos referiremos al intenso proceso de radicalización que se desarrolló entre los activistas y bases de Perkins. Para ello describiremos las estrategias discursivas y los posicionamientos políticos del SITRAP. A partir de diversas fuentes documentales reconstruiremos este proceso fundamental para comprender la complejidad del clasismo en Córdoba.

A inicios de 1973 el clima político nacional y provincial estaba dominado por la euforia producida por el retorno del peronismo al gobierno y en la "Córdoba rebelde", principal bastión de la lucha contra la dictadura, por la asunción de un gobierno de izquierda donde junto al gobernador Ricardo Obregón Cano, se ubicaba Atilio López, Secretario General de la CGT Regional y referente del sindicalismo combativo. En este escenario se destaca la temprana definición del SITRAP por el clasismo. Por ejemplo, en un reportaje publicado por la revista "Posición" en febrero de 1973, los nuevos dirigentes plantean las estrategias que permitirán avanzar en dicho proyecto:

La vanguardia, el sector más esclarecido de los trabajadores de Perkins, llevará adelante la lucha contra la burocracia, la patronal y contra la dictadura; pero el hecho de que nosotros lo impulsemos, no significa que debamos aferrarnos ciegamente a ello. Si las circunstancias están dadas para marcharporesta senda y en la medida que la sigan a sudirección, se podrá llevar adelante el sindicalismo combativo y clasista. Será necesario aprender y asimilar las experiencias que se dieron tanto en SITRAC-SITRAM y el SMATA. Se deberá trazar una perspectiva de trabajo de acuerdo a las características particulares de los trabajadores de Perkins y en forma consciente y segura poder seguir adelante. Las bases no toman conciencia de un día para otro, sino que es todo un proceso para que a esto se
38. BS, N. 5, 10/1973, pp. 3 y 4 .

39. BSE, 04/1974, p. 89. 
40. Archivo de El Topo Blindado, Revista Posición N.으 3, 02/1973, pp. 30 a 32 .

41. BS, N. 1, 25/o4/1973, p. 1.

42. Ibídem, p. 4. llegue. Más si se tiene en cuenta que la mayoría de los trabajadores de Perkins por más de 9 años estuvieron bajo la influencia de la burocracia, entonces para inculcar la idea y la fuerza de un sindicato combativo y clasista llevará algún tiempo, y esto habrá que tenerlo en cuenta. ${ }^{40}$

Un paso fundamental en el proceso de intensa politización que llevó adelante la nueva conducción se concretó con la publicación a partir del 25 de abril del periódico "SI. TRA.P Boletín informativo del Sindicato de Trabajadores de Perkins". Se impuso, al mismo tiempo, una nueva denominación para la entidad gremial. Este gesto simbólico también era útil para marcar las diferencias con el "viejo sindicato". En la declaración de principios "El porqué de este Boletín" se considera a la prensa sindical un "instrumento de comunicación entre nosotros los obreros, para así formar un sindicato de clase que responda a nuestros intereses, que son en su conjunto, los de la clase obrera". Completando la primera página de este primer número, se ubica un texto -en mayúsculas y negrita- que informa sobre las prioridades de la nueva dirección. En momentos de euforia y triunfalismo por el cambio político que significaba el retorno del peronismo al gobierno el sindicato privilegiaba concentrarse en sus demandas al plantear:

Exigir al nuevo gobierno la reincorporación de todos los despedidos de los últimos años que han luchado contra la dictadura militar y la explotación capitalista. Ni un paso atrás, hasta conquistar: Salarios dignos y demás reivindicaciones. Una nueva revaluación de categorías. La libertad de todos los presos políticos. Una CGT que defienda nuestros intereses de clase. ${ }^{41}$

También se destaca en este primer número un artículo de carácter histórico -frecuentes en la prensa obrera del periodo- titulado " $1^{\circ}$ de Mayo". En él se considera oportuno dar a conocer el origen de esta gesta proletaria y, fundamentalmente, se postula una clara distinción con respecto a la tradición peronista sobre esta fecha:

...la burguesía de nuestro país se ha esforzado por borrar de la historia las luchas del Movimiento Obrero Argentino. El $1^{\circ}$ de Mayo es una fecha de la clase obrera de todo el mundo. Pero no es -como quiere hacernos creer la burguesía- (los patrones) un día de fiesta, ¡No! En el $1^{\circ}$ de Mayo se recuerda a los mártires de las luchas obreras, que dejaron sus vidas para arrancar las jornadas de ocho horas. En nuestro país se le ha quitado a esta fecha su verdadero sentido. Se le ha dado el carácter de día "festivo", de "unión nacional", de conciliación entre "el capital y el trabajo", etc. NADA MÁS FALSO QUE ESTO. ${ }^{42}$

El Boletín Extra aparecido en abril de 1974 es fundamental para analizar el discurso radicalizado del SITRAP. Exponemos dos artículos donde se identifican los rasgos principales del sindicalismo tradicional peronista y los alternativos que presenta el modelo clasista.

En el artículo "Que se entiende por burocracia sindical" se caracteriza a esta como una forma de conducción gremial "enquistada" en los sindicatos obreros. Se denuncia: su "carácter traidor" como consecuencia de "defender sus propios intereses económicos (...) en lugar de actuar representando los intereses del conjunto de los trabajadores", su alejamiento de las bases por "no trabajar en la fábrica" y su conversión en "funcionarios", burócratas, para negociar con las empresas. También su poder económico "por las coimas que cobran por el manejo de los fondos sindicales (obras sociales, publicidad), o que reciben de las patronales para "solucionar" ciertos problemas o, directamente por el robo directo de los fondos sindicales". Por último, sobre su rol político se señala que: "lo único que hicieron en esa época fue conciliar con los gobiernos de turno y con las patronales para no perder (...) sus sillones 
sindicales". Frente a esta situación "las épocas de lucha (...) las nuevas etapas que se abren barrerán con las burocracias traidoras enquistadas en los sindicatos obreros". 43

En el segundo artículo "Sindicalismo Clasista" se sostiene que en el modelo sindical tradicional "la misión (...) de tratar de mejorar nuestra situación ha sido deformada, desnaturalizada. El sindicato se ha transformado en mediador entre los obreros y los patrones, o directamente en agente de la patronal". Esta evolución tiene relación con algunos de los principales postulados del peronismo: la conciliación de clases y la redistribución del ingreso:

Esto ha sido posible, porque entre los dirigentes sindicales y delegados gremiales, predominaba la ideología burguesa, que la clase dominante mete en la cabeza de los trabajadores para mantener su dominio y explotación. Yestas ideas son las que dicen que puede haber conciliación entre capital y trabajo, es decir, entre explotadores y explotados. Son las ideas que dicen que siempre hubo ricos y pobres y siempre seguirá habiendo. Y por eso dicen que el asunto es repartir mejor lo producido. ${ }^{44}$

Por el contrario, se sostiene que en el sindicalismo clasista:

...donde todos somos iguales, todos tenemos los mismos derechos y las mismas responsabilidades. Y la asamblea es el órgano máximo de decisión (...) ejemplo son las numerosas asambleas para discutir cada uno de los conflictos con la empresa y para decidir en conjunto las medidas de lucha a tomar. Resultado de estos métodos son las importantes conquistas logradas, la UNIÓN Y LA CONCIENCIA de los trabajadores de Perkins. ${ }^{45}$

También en el discurso del SITRAP está presente la referencia al socialismo como proyecto político. La función del sindicato debe trascender la tarea reivindicativa y afrontar la lucha política. En este sentido, en el artículo "Cordobazo" se plantea:

...continuar la lucha y la movilización, como la única forma de lograr la tan ansiada transformación de la sociedad, eliminando de raíz y para siempre, la injusticia, la desigualdad, con su secuela de miseria, con la mira puesta en la toma del poder por la clase obrera para la construcción de un nuevo modelo de sociedad: la sociedad socialista. En ese camino, los compañeros de Perkins, unidos con los demás trabajadores y sectores populares, nos hallamos profundamente comprometidos y no pararemos en nuestra lucha hasta vernos completamente liberados de la explotación y opresión capitalista. ${ }^{46}$

Otro aspecto relevante de la radicalización política se relaciona con los posicionamientos del SITRAP frente a los proyectos e iniciativas de los sucesivos gobiernos peronistas. Por ejemplo, frente a la decisión de decretar la caducidad de los mandatos de las regionales de la CGT, el SITRAP fijó su posición a través del volante "La Comisión Directiva y el Cuerpo de Delegados del Sindicato de Perkins al pueblo de Córdoba":

Ante la resolución de la CGT Nacional que deja sin efecto los actuales Secretariados de todas las regionales de la CGT en el país, a partir del $1^{\circ}$ de julio, NUESTRO SINDICATO, se dirige a la clase trabajadora y el pueblo de Córdoba, para repudiar el manejo burocrático y verticalista de la CGT Nacional, que pretende de esa manera poder controlar desde Buenos Aires, todo el movimiento obrero del Interior, sometiéndolo a su política claudicante al servicio del Pacto Social celebrado con las patronales explotadoras. Los Señores como Rucci, Calace, Miguel, etc., que hoy pretenden dirigir la mal llamada NORMALIZACIÓN de las regionales, fieles a la política de conciliación no vacilan en seguir trenzando y pactando, celebrando congresos siempre a espaldas de los obreros y trabajadores. ${ }^{47}$
43. BSE, 04/1974, p. 10.

44. BSE, 04/1974, p. 117.

45. Ibídem, p. 118.

46. BSE, 04/1974, p. 29.
47. “La Comisión Directiva y Cuerpo de Delegados del Sindicato de Perkins, al pueblo de Córdoba", Volante difundido por el SITRAP en junio de 1973. 
48. Revista Nuevo Hombre N. 44, 12/07/1973, pp. 5 y 6 en Nuevo Hombre Tomo II, Edición facsimilar, pp. 161 y 162. Buenos Aires: Biblioteca Nacional, 2015.

49. Frente Revolucionario Peronista, Acción Revolucionaria Peronista,

Peronismo de Base, El Obre-

ro, Socialismo Revolucionario,

Espartaco, Grupo Praxis, Cristianos por el Socialismo y otros.

50. Columnas FAL América en Armas, FAL-CHE, Ejercito Libertador Nacional, Comandos Populares de Liberación y otros.

51. Documento político y programa del VI Congreso del FAS (Silva Mariños, 2017: 293).

52. Abel Bohoslavsky, Médico colaborador del SITRAP y militante del PRT-ERP. Entrevista realizada en Buenos Aires en diciembre de 2014. Entrevistador: Diego Salerno.
Es relevante, en el análisis de la experiencia clasista del SITRAP, considerar la vinculación de sus activistas con las diversas organizaciones de la izquierda revolucionaria. De acuerdo a los testimonios obtenidos podemos señalar que tres partidos fueron los que lograron mayor inserción e influencia en las bases de Perkins: El Obrero, el Partido Revolucionario de los Trabajadores (PRT-ERP) y el Peronismo de Base. También, es posible identificar la presencia de militantes del "peronismo combativo" e incluso del FIP (Frente de Izquierda Popular).

Esta relación entre activistas y agrupaciones políticas favoreció la participación del SITRAP en los intentos de organizar frentes sindicales y políticos: Nos referimos al Movimiento Sindical de Base (MSB) y al Frente Antiimperialista por el Socialismo (FAS). Con relación al primero, fue impulsado por varias tendencias de izquierda revolucionaria -aunque hegemonizado por el PRT-ERP- como una propuesta para constituir una "alternativa de organización y combate para las más amplias masas obreras, ya sea activistas independientes, sindicatos o agrupaciones de distintas orientaciones políticas" (Stavale y De Santis, 2016: 36). Fue presentado durante el Primer Plenario Nacional para la Defensa y la Recuperación Sindical realizado el 8 de julio de 1973. Participaron del mismo, entre otros, el Sindicato de Trabajadores de Perkins, Luz y Fuerza, SMATA, Construcción, Municipales, Asociación de Periodistas, Viajantes, Docentes, Sindicato del Vidrio y Cerveceros. En su extenso discurso, Agustín Tosco concentró sus críticas en el Pacto Social y auguró por la profundización del enfrentamiento a las políticas del gobierno peronista: "hoy no es posible meter en la cabeza de la gente la idea de concretar un pacto social y la conciliación de clases, porque la clase obrera y el pueblo se están dando una política con contenido revolucionario, con contenido de clase". ${ }^{8}$

Por su parte en relación al FAS, el objetivo de lograr la unidad formó parte de la estrategia de la izquierda revolucionaria de la época (Silva Mariños, 2017). Esta nueva iniciativa fue apoyada por organizaciones políticas ${ }^{49}$ y político-militares, ${ }^{50}$ organizaciones populares, sindicales y de trabajadores, grupos culturales y publicaciones. Contó con la participación de Agustín Tosco, Silvio Frondizi, Alicia Eguren y Armando Jaime y realizó tres congresos nacionales entre 1973 y 1974. Este frente convocaba a: "unir a todas las fuerzas del conjunto de este pueblo, ya sean socialistas, comunistas, peronistas, progresistas y revolucionarios, radicales y cristianos de izquierda, y demás sectores que estén interesados en hacer la revolución contra la gran burguesía, la oligarquía y el imperialismo e instaurar un gobierno obrero y popular socialista (...)".51

A partir de diversas fuentes y testimonios es posible confirmar la participación del SITRAP en los congresos del FAS realizados en Tucumán y Rosario. Por ejemplo, en el siguiente relato se describen aspectos de esa experiencia:

El FAS convoca a un congreso en Tucumán que se hizo en agosto de 1973. Desde Córdoba organizamos una caravana con muchos ómnibus. Uno de ellos, era de obreros de Perkins, algunos de los cuales fueron con familiares. Recuerdo nuestra entrada a Tucumán entonando ‘Córdoba, obrera, clasista y guerrillera' (...) Al regreso del congreso del FAS, realizamos una reunión con algunos obreros que habían concurrido. La hicimos en la casa del 'León Manso', Víctor Hugo González. Él -como otros- ingresaron al PRT, recuerdo al 'gallego' Apontes, al Pacho Figueroa, al Negro Puchetta, al Cacho (...) Al año siguiente, en junio de 1974, cuando se hizo otro congreso del FAS en Rosario, también viajamos en ómnibus con muchos compañeros de Perkins. En resumen, el FAS tenía cierta presencia política en esta fábrica. ${ }^{52}$

Otras experiencias formaron parte del repertorio de proyectos y acciones que nutrían a los activistas del SITRAP. Entre ellas, las vinculadas con los medios de prensa. Una de las principales publicaciones políticas de Córdoba fue la revista "Posición". Sus directores fueron Eugenio Pettigiani y Nelso Del Vechio y su propósito era "Llegar 
a todos los sectores de la población, en forma directa, incursionando en todos los temas de interés general, pero con claro y definido sentido social". Se editó entre diciembre de 1972 y julio de 1974 y su dirección se hallaba en la calle Brasil 670 "B". Con una tirada de cinco mil ejemplares era el vocero legal del FAS. Además, en su sede se editaba el boletín del SITRAP, siendo responsable de esta tarea José Apontes.

Según el testimonio de Julio Carreras:

Un grupo de 'notables', de número variable, aunque por general no menos de diez personas, se reunía para aprobar el temario para las ediciones de la revista y luego para revisar los artículos de cada número. Junto a representantes de cada fuerza que constituía el FAS participaban también, el 'Negro' Villa, por el Sindicato de Perkins, Roberto Campbell, por el Movimiento Sindical Combativo y el 'Negro' Gregorio Flores por SITRAC-SITRAM. ${ }^{53}$

También, se participó en la organización, en enero de 1974, de una Coordinadora de Publicaciones Populares. Formaron parte de la misma el Sindicato de Perkins ("Boletín del SITRAP", representado por Juan Villa), el sindicato de Prensa ("El Trabajador de Prensa"), Luz y Fuerza ("Electrum"), SMATA y las publicaciones "Posición", "Patria Nueva", entre otros medios de prensa. ${ }^{54}$

De esta manera, los militantes obreros del SITRAP fueron participes del intenso proceso de radicalización de amplios sectores de la sociedad cordobesa. Junto a diversos actores políticos y sociales (periodistas, abogados, estudiantes, activistas políticos y de las organizaciones armadas), multiplicaron iniciativas tendientes a extender y coordinar la movilización y la toma de conciencia de la clase obrera y sectores del pueblo y mantener vigente un proyecto revolucionario.

\section{Conclusiones}

En nuestro trabajo hemos intentado mostrar que la experiencia de los trabajadores del Sindicato de Perkins formó parte de la expansión del clasismo en el movimiento obrero de Córdoba. Influidos por la centralidad de SITRAC-SITRAM y el crecimiento de la izquierda revolucionaria sus jóvenes y audaces activistas protagonizaron una nueva fase del sindicalismo revolucionario a partir de 1973. Desarrollaron un modelo sindical de democracia obrera basado en la participación de las bases para la toma de decisiones y el recurso a la acción directa para sostener sus demandas ante la patronal. Además, desde sus tempranas posturas quedó definida su radicalización política e ideológica. También, fueron concretas sus críticas hacia las políticas del gobierno nacional, en especial, el Pacto Social, la ley de Asociaciones Profesionales y el control de la CGT Regional. Por otra parte, definieron su inserción en el movimiento obrero local a partir de su integración a la CGT regional y su participación en la alianza combativa con Tosco, López y Salamanca. En especial, la solidaridad obrera ocupó un lugar relevante como lo demuestran la crucial participación durante el conflicto por la afiliación de los trabajadores de Fiat entre el SMATA y la UOM y el apoyo a los incipientes núcleos combativos en varios sindicatos.

Estos rasgos sintetizan la experiencia del Sindicato de Trabajadores de Perkins. Podemos sostener que este movimiento clasista ocupa un lugar de relevancia en la rebelión de las bases en la Córdoba rebelde. De igual forma, y como planteo a desarrollar en futuros trabajos, estos atributos presentes en las bases de Perkins permiten reflexionar sobre la capacidad de resistencia que ayudó a sostener una conducción clasista en el SITRAP luego del descabezamiento de los sindicatos líderes en 1974 y protagonizar importantes luchas obreras durante la etapa final del gobierno peronista.
53. Julio Carreras. Luz de Agosto. En http://Fulgor.Blogspirit.com, 2013. Militante del PTR-ERP y editor de la revista "Posición" de Córdoba.

54. Archivo El Topo Blindado, Revista Posición N.ํ11, 01/1974, pp. 6 y 7. 


\section{Q Bibliografía}

》Brennan, J. (1996). El Cordobazo. Las guerras obreras en Córdoba, (1955-1976). Buenos Aires: Sudamericana.

"Brennan, J., Gordillo, M. (2008). Córdoba Rebelde. El Cordobazo, el clasismo y la movilización social. La Plata: De la campana.

»Ferrero, R. (1995). El Navarrazo y el gobierno de Obregón Cano. Córdoba: Editorial Alción.

» Flores, G. (1994). SITRAC-SITRAM. Del Cordobazo al clasismo. Buenos Aires: Ediciones Magenta.

"Gordillo, M. (ed.) (2001). Actores, prácticas, discursos en la Córdoba combativa. Una aproximación a la cultura política de los `7o. Córdoba: Ferreyra Editor.

» James, D. (1990). Resistencia e integración. El peronismo y la clase trabajadora argentina, 1946-1976. Buenos Aires: Sudamericana.

»Laufer, R. (2017). “El clasismo en el SMATA Córdoba, 1966-1972”, en Rupar, B., Costilla, A. y Galafassi, G. (Coords.). Dirán hubo gigantes aquí. Izquierda, peronismo y clase obrera en los '6o y '70. Buenos Aires: GEACH-UNQUI.

» Mignon, C. (2014). Córdoba obrera. El sindicato en la fábrica 1968-1973. Buenos Aires: Imago Mundi.

»Ortiz, M. L. (2015). Violencia y represión. Los trabajadores clasistas en Córdoba,1969-1976 (Tesis de Doctorado inédita). Facultad de Filosofía y Letras, Universidad de Buenos Aires.

»Schmucler, H., Malecki, S. y Gordillo, M. (2014). El obrerismo de Pasado y Presente. Documentos para un Dossier no publicado sobre SiTrac - SiTram. Villa María: Eduvim.

» Servetto, A. (1998). De la Córdoba combativa a la Córdoba militarizada 1973-1976. Córdoba: Ferreyra.

» Silva Mariños. L. (2017). Frente Antiimperialista por el Socialismo. Un ejército político de masas impulsado por el PRT. Buenos Aires: La Llamarada.

"Stavale, S. y De Santis, D. (2016). Un partido de la clase obrera. La política del PRT-ERP en el movimiento obrero. Buenos Aires: A Formar Filas. Guevarista.

» Tejerina, H., Roitman, S., Cabral, X.; Olivera, E. (2010). El torno y la molotov. Relatos e imágenes de la Córdoba obrera 60-70. Córdoba: Universitas - Jorge Sarmiento.

»Torriglia, J., Fracaroli, L. (2016). Una ruta al hombre nuevo. Memorias de lucha y conquistas del Sindicato de Perkins en los`7o, en las voces de los protagonistas. Córdoba: Ediciones del Pasaje. 